Not surprisingly, it is a very mixed bag. Most scientists will have some instant nominees for great inventions: the lens, printing, the digital computer, artificial light, the gun, the contraceptive pill - and indeed, all of these are present. Other less obvious candidates, persuasively argued in these pages, include hay, the stirrup, paper, the mirror, distillation. There are some staggering omissions - mechanical power, radio. And the book is sadly flawed by many casual, bitty entries unworthy of the topic.

It seems clear that the thinkers were held to no clear remit. The entries include inventions physical (the battery), procedural (scientific method), social (the university), intellectual (arabic numerals) and even imaginary (the unknown benisons confidently expected to flow from genetic sequencing).

Neither has the editor demanded that his leading thinkers justify their title. Many, indeed, think intelligently about their field, consider the history of the past two millennia and what greatness means in an invention, before presenting an argument for the invention of their choice. But others are allowed to get away with a few scrappy, thoughtless sentences. One thinker champions "the construction of autonomous tools", but in 34 lines gives no clue as to what this means, if anything, or whether it has yet been achieved. Another, in just four lines, champions the printing press to avoid upsetting the editor, and the Thermos bottle for no reason. Another nominates television, but remarks of this pervasive, socially transforming invention merely that it provides information, influences patterns of behaviour such as sex and crime, and has reduced the popularity of live performances. Another leading thinker, in the course of a long and rambling rant against the whole idea of invention, states (without explaining why it is relevant to the topic in hand) that he "doesn't think he could hack... assholes and complacent dopes living hundreds of years".

The inclusion of such sloppy and demeaning language is an extreme instance of editorial neglect of duty. But the book as a whole suffers from the lack of a consistent voice. Many entries, for example, address conversational remarks to the editor, or to other contributors. To present such casual random chatter in book form is discourteous to readers outside the charmed circle. And, given the mighty computer power available to all concerned, the lack of any index or contents classification suggests further neglect. One invention celebrated in the book is the eraser in its many forms. It even features on the dust-jacket. It should have been wielded far more vigorously inside.

David Jones is in the Department of Chemistry,

University of Newcastle upon Tyne,

Newcastle upon Tyne NE1 7RU, UK.

\title{
At one with nature
}

Arno Rafael Minkkinen, a teacher of photography, has attempted to express the relationship of our body to the land it inhabits, through a collection of self-portraits. His naked body is depicted in a range of isolated settings, emphasizing its bond with the natural world. The collection, called Body Land (Smithsonian Institution Press, \$24.95,

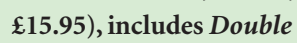
Delicate Arch, shown here, taken in Moab, Utah.

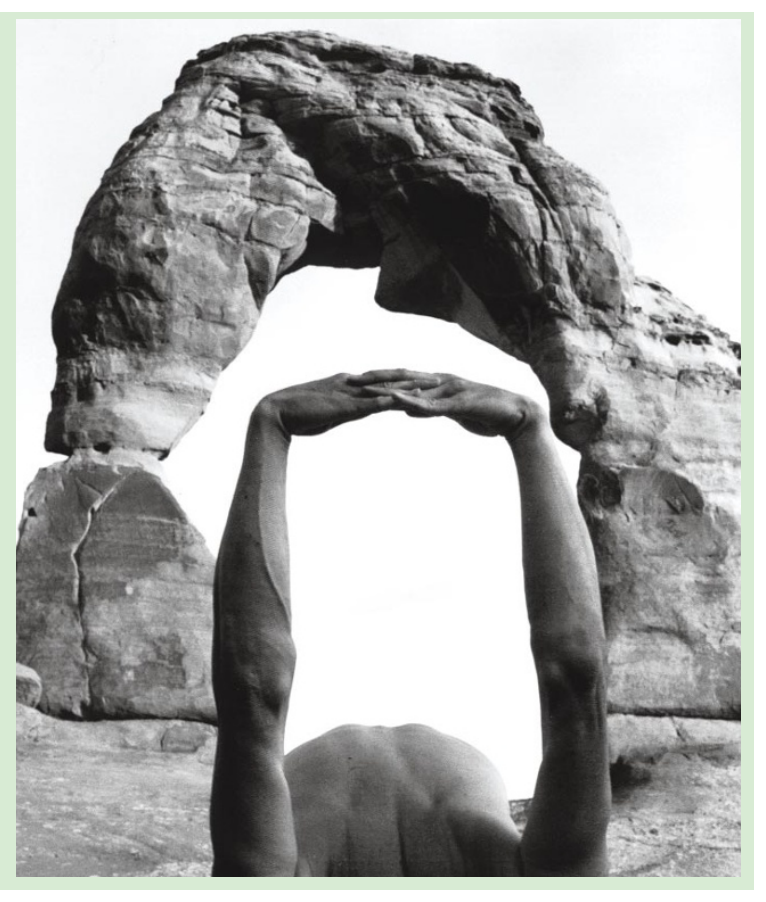

\section{A view of figures through the ages}

\section{The Human Body: Image and}

\section{Emotion}

by I. Philippe Comar

Thames \& Hudson: 1999. 159 pp. 26.95 (pbk)

\section{Ludmilla Jordanova}

The Human Body is not a book about science, nor is it written by a scientist, yet it touches on scientific and medical questions at many points. The author is an artist with an interest in the representation of the human body. This is a huge field and, accordingly, the book covers a long time span, essentially the beginnings of art to the present day.

Philippe Comar includes diverse images from the expected anatomical drawings and nudes to carvings, photographs, Greek statues, wax models, drawings and various items of art that use the human figure in some way. The illustrations are of a high quality and, although some will be familiar to most readers with an interest in the body, many are not, and hence their reproduction in this accessible, low-cost form is to be welcomed.

The organization of the book is unusual and rather unsatisfying. Pages are crammed with pictures, the main text and quotations. Each image also has a caption which responds to it in some way rather than being purely factual. This is indicative of the book's overall approach. It consists of five essays, which are meditations on themes such as "the outraged body" and "embodying desire". Each one ranges freely in time and space, and their titles tell the reader nothing about their content.

At the end of the book, there is a short section comprising extracts from texts and supplementary pictures. It is clear that it is partly to be read for pleasure and partly to be used as a compilation of sources and ideas, although it makes no claims to be systematic.

The question of how, over many centuries, the human body has been a central concern for fields we now differentiate as art, medicine and science is formidably complex. These intersections have become a fashionable subject, but here they are often dealt with superficially. This is not an intellectually deep book.

It originally formed part of a series developed by the French publishers Gallimard, and it is fully in keeping with the significance accorded to haute vulgarisation in France. When done well, books that are heavily illustrated, well written and informative perform an invaluable service, as long as readers know what they are getting.

Although not a scholarly work, it is thought-provoking and I came across only one topic, physiognomy, that I felt was presented misleadingly. Because of its association with racial classifications, this is always a difficult subject to handle well. A more intellectually rigorous account would have to pay considerable attention to the contexts in which specific views of the body were generated, which is all but impossible in works of this type. Hence Comar's visual and verbal essays have their merits, as long as they are taken as being personal responses rather than authoritative scholarship.

The challenge of writing about the longstanding, intricate and fascinating intersections between the visual arts and knowledge of the human body, in a way that both does them justice and is accessible, remains.

Ludmilla Jordanova is at the School of World Art Studies and Museology, University of East Anglia, Norwich NR4 7TJ, UK. 